\title{
Intraoperative fluorescence angiography as an independent factor of anastomotic leakage and a nomogram for predicting leak for colorectal anastomoses
}

\author{
Mikhail Alekseev ${ }^{1,2}$, Evgeny Rybakov ${ }^{1}$, Evgeniy Khomyakov ${ }^{1,2}$, Irina Zarodnyuk ${ }^{1}$, Yuri Shelygin ${ }^{1,2}$ \\ ${ }^{1}$ Department of Oncoproctology, Ryzhikh National Medical Research Center of Coloproctology, Moscow; ${ }^{2}$ Department of Coloproctology, \\ Russian Medical Academy of Continuous Professional Education, Moscow, Russia
}

Purpose: Colorectal anastomotic leakage (AL) is a life-threatening complication, which increases morbidity, hospital stay and cost of treatment. The aim of this study is to identify risk factors, including intraoperative indocyanine green fluorescence angiography (ICG FA), associated with the leak of stapled colorectal anastomosis.

Methods: Four hundred twenty-nine consecutive patients underwent surgery between 2017 and 2019 for benign $(n=10$, $2.3 \%)$ or malignant $(n=419,97.7 \%)$ and rectal $(n=349,81.4 \%)$ or distal sigmoid $(n=80,18.6 \%)$ lesions with double-stapling technique reconstruction were included into retrospective study. Univariate analysis and multivariate logistic regression of the tumor-, patient- and treatment-related risk factors of AL was performed.

Results: An AL developed in 52 patients (12.1\%). In multivariate analysis following variables were independently associated with $\mathrm{AL}$; male sex (odds ratio [OR], 3.8; 95\% confidence interval $[\mathrm{CI}], 1.9-7.7 ; \mathrm{P}<0.01$ ), anastomosis at $\leq 6.5 \mathrm{~cm}$ from anal verge (OR, 3.1; 95\% CI, 1.3-7.5; $\mathrm{P}=0.01)$, and age of $\leq 62.5$ years (OR, 2.1; 95\% CI, 1.1-4.1; $\mathrm{P}=0.03)$. ICG FA was found as independent factor reducing colorectal $\mathrm{AL}$ rate $(\mathrm{OR}, 0.4 ; 95 \% \mathrm{CI}, 0.2-0.8 ; \mathrm{P}=0.02)$. A nomogram with high discriminative ability (concordance index, 0.81 ) was created.

Conclusion: ICG FA is a modifiable surgery-related risk factor associated with a decrease of colorectal AL rate. A suggested nomogram, which takes into consideration ICG FA, might be helpful to identify the individual risk of AL.

Keywords: Anastomosis leakage; Colorectal anastomosis; Indocyanine green; Risk factors; Nomograms

\section{INTRODUCTION}

Colorectal anastomoses became a routine procedure in surgery after introduction of circular staplers (Russian gun) in the late 1960s [1] and the double-stapling technique in the 1980s [2]. Despite the advances in surgical technique and perioperative management of patients, an anastomotic leakage (AL) remains urgent problem of colorectal surgery $[3,4]$.

Received: Mar 6, 2021 - Revised: Apr 27, 2021 • Accepted: May 2, 2021

Correspondence to: Evgeniy Khomyakov, M.D.

Department of Oncoproctology, Ryzhikh National Medical Research Center of Coloproctology, Saljam Adilja St. 2, 123423 Moscow, Russia

Tel: +7-9260248888

E-mail: evgeniy.khomyakov@gmail.com

ORCID: https://orcid.org/0000-0002-3399-0608

(C) 2022 The Korean Society of Coloproctology

This is an open-access article distributed under the terms of the Creative Commons Attribution NonCommercial License (https://creativecommons.org/licenses/by-nc/4.0) which permits unrestricted non-

commercial use, distribution, and reproduction in any medium, provided the original work is properly cited.
The main prerequisites for successful anastomosis are adequate blood supply, good stapling technique, and absence of tension between anastomosed intestinal segments. There are a number of AL risk factors [5-7] mentioned in a number of published papers. Though a lot of them are conflicting, such risk factors as level of anastomosis over anal sphincter, sex, obesity, smoking, and use of steroids, preoperative chemoradiotherapy (CRT) as well as intraoperative blood loss and postoperative blood transfusion are considered as significant in most of the published series. On the other hand, reinforcement of anastomosis [8], transanal tube $[9,10]$, or biodegradable soft sheath (C-seal) [11] of the anastomosis remains the methods with unproven effectiveness. In recent years, the new method, indocyanine green (ICG) fluorescence angiography (FA), was introduced into surgical practice for blood supply quality assessment. The Pillar II Study was demonstrated an AL rate of $1.9 \%$ for low anastomoses and/or after pelvic radiation [12]. Another phase II multicenter study [13] reported on AL rate of 3\% for low colorectal anastomoses. This is a very low rate of AL. 
Though AL is hardly ever will be avoided entirely, a good prediction tool would be helpful for surgeon and patient decision to avoid anastomosis at all. Several nomograms have been developed to predict AL after surgical treatment of rectal cancer [14-16]. The purpose of presented retrospective single-center study was to develop a new nomogram for prediction of $\mathrm{AL}$ of colorectal anastomosis, which included novel method of ICG FA.

\section{METHODS}

A retrospective analysis of database collected prospectively between March 2017 and August 2019 was performed. The inclusion criteria was the formation of a colorectal anastomosis with a double-stapling technique for benign or malignant tumors of rectum or distal sigmoid. All operations were conducted by 3 colorectal surgeons who perform more than 50 colorectal resections per year. Ethical approval for the trial protocol was obtained from the local independent ethics committee of State Scientific Centre of Coloproctology (No. N80, 02.02.2017). All participants provided written informed consent prior to enrolment in the study.

An anastomotic leak was defined in accordance with proposal of the International Study Group of Rectal Cancer [17]. An AL was defined as any defect of the colorectal anastomotic site leading to a communication between the intra- and extraluminal compartments. It was graded as follows: grade A is an AL requiring no active therapeutic intervention, grade $\mathrm{B}$ is $\mathrm{AL}$ requiring active therapeutic intervention but manageable without relaparotomy, and grade $\mathrm{C}$ is AL requiring relaparotomy. The clinical and radiological AL was confirmed by contrast enema or computed tomography scan in all patients within 30 days after surgery.

Since March 2017, we started to use ICG FA for assessment of the perfusion of the anastomosis. A sterile water-soluble lyophilized powder of ICG (Pulsion Medical Systems, Munich, Germany) was used. After the surgeon's selection of the transection level of the colon for anastomosis of surgeons ICG was injected intravenously at a dosage of $0.2 \mathrm{mg} / \mathrm{kg}$. A FA was performed using laparoscopic system (Karl Storz SE \& Co., KG, Tuttlingen, Germany) 2 to 3 minutes after ICG injection. If uniform blue glow emission was detected from ICG injection, the site of colon chosen for anastomosis creation would estimate as well perfused. If the fluorescence was equivocal or absent the colon was regarded as poorly perfused and surgeon had to change a transection line in a proximal direction up to the level of adequate blood supply. For reinforcement anastomosis, we placed 6 to 8 interrupted sutures along the staple line circumferentially.

\section{Statistics}

The univariate associations were tested with Pearson chi-square test. A P-value less than 0.05 was considered statistically significant. All independent variables with $\mathrm{P} \leq 0.05$ in the univariate analysis were subsequently included in a multivariate stepwise logistic regression model to determine risk factors associated with
AL after controlling for covariates with $\mathrm{P}<0.1$. Optimal cutoff points were defined by the receiver-operating curve analysis with Youden index calculation. Statistical analysis was performed using GraphPad Prism ver. 8.3 (GraphPad Software, La Jolla, CA, USA). The nomogram of AL was created based on multivariate logistic regression analysis and constructed using the "rms" package (http://www.r-project.org/).

\section{RESULTS}

Results of 429 resections for rectal lesion with colorectal anastomosis were analyzed. Table 1 shows patients' demographic, clinical, and surgery characteristics. Of 429 tumors, 349 (81.4\%) were located in rectum and 80 (18.6\%) localized above $15 \mathrm{~cm}$ from anal verge as measured by rigid proctoscope. Forty-six of rectal carcinomas (10.7\%) underwent neoadjuvant CRT of 45 to $54 \mathrm{cGy}$ in 4 to 5 weeks with 5 -fluorouracil or capecitabin. Subsequent surgery was performed 6 to 10 weeks later. In 40 cases (9.5\%), stage IV of colorectal cancer was diagnosed due to synchronous liver metastases. Simultaneous metastasectomy was performed in 20 of them and the rest of the patients with hepatic lesions were scheduled for subsequent liver surgery. Resection of adjacent organs was necessary in 49 patients $(11.4 \%)$ and a final pathology demonstrated R0 resection in 403 (93.9\%).

ICG FA was performed in 239 patients (55.7\%) and resulted in the change of transection line in 50 of 239 cases (20.9\%).

All patients had stapled colorectal anastomosis and median distance of anastomosis from anal verge was $8 \mathrm{~cm}$ (range, 4-15 cm). Of them, 252 of 429 (58.7\%) located between 4 and $8 \mathrm{~cm}$ and 177 of 429 (41.3\%) located between 9 and $15 \mathrm{~cm}$. Air leak test of anastomosis performed in 360 of 429 patients (83.9\%) and it was positive in 54 of 360 patients (15.0\%). Reinforcement of anastomosis was done in 223 of 429 (52.0\%) patients and defunctioning ileostomy was fashioned during surgery in 307 patients (71.6\%).

An AL was developed in 52 patients (12.1\%). The rate of AL grade A (asymptomatic radiological) was $7.5 \%$ (32 of 429 ). The rates of AL grade B and C were 3.0\% (13 of 429) and 1.6\% (7 of 429), respectively. The median postoperative hospital stay was 9 days (range, 4-32 days).

In the univariate analysis (Fig. 1) of patient-related risk factors of $\mathrm{AL}$, male sex (odds ratio [OR], 4.1; 95\% confidence interval [CI], $2.1-7.9 ; \mathrm{P}=0.001)$ and age of $\leq 62.5$ years $(\mathrm{OR}, 1.9 ; 95 \% \mathrm{CI}$, $1.0-3.4 ; \mathrm{P}=0.04$ ) were associated with a higher risk of $\mathrm{AL}$, while body mass index, American Society of Anesthesiologists physical status classification, diabetes mellitus, and smoking had no influence on $\mathrm{AL}(\mathrm{P}>0.05)$. Among treatment-related risk factors preoperative CRT (OR, 3.0; 95\% CI, 1.4-6.3; $\mathrm{P}=0.003$ ), total mesorectal excision (OR, 7.9; 95\% CI, 3.1-20.3; $\mathrm{P}=0.001$ ), colorectal anastomosis located at $\leq 6.5 \mathrm{~cm}$ from anal verge (OR, 5.7; 95\% $\mathrm{CI}, 2.9-11.1 ; \mathrm{P}=0.001)$, $\mathrm{R} 1$ resection $(\mathrm{OR}, 2.9 ; 95 \% \mathrm{CI}, 1.1-7.3$; $\mathrm{P}=0.02)$ and the formation of a preventive stoma (OR, 7.5; $95 \%$ $\mathrm{CI}, 2.3-24.7, \mathrm{P}=0.001$ ) demonstrated significant association with 
Table 1. Characteristics of patients and surgery

\begin{tabular}{|c|c|c|c|}
\hline Characteristic & Total & $\mathrm{AL}$ & $\mathrm{P}$-value for $\mathrm{AL}$ \\
\hline \multicolumn{4}{|l|}{ Patients' factor } \\
\hline No. of patients & $429(100)$ & $52(12.1)$ & \\
\hline \multicolumn{4}{|l|}{ Sex } \\
\hline Male & $199(46.4)$ & 39 (19.6) & $<0.001^{*}$ \\
\hline Female & $230(53.6)$ & $13(5.7)$ & \\
\hline \multicolumn{4}{|l|}{ Age (yr) } \\
\hline$\leq 62.5$ & $206(48.0)$ & 32 (15.5) & $0.040^{\star}$ \\
\hline$>62.5$ & $223(52.0)$ & $20(9.0)$ & \\
\hline \multicolumn{4}{|l|}{ ASA PS classification } \\
\hline I-II & $51(11.9)$ & $8(15.7)$ & 0.370 \\
\hline III & $378(88.1)$ & $44(11.6)$ & \\
\hline \multicolumn{4}{|l|}{ Smoking status } \\
\hline Yes & $71(16.6)$ & $14(19.7)$ & 0.130 \\
\hline No & $246(57.3)$ & $31(12.6)$ & \\
\hline Unknown & $112(26.1)$ & & \\
\hline \multicolumn{4}{|c|}{ Body mass index $\left(\mathrm{kg} / \mathrm{m}^{2}\right)$} \\
\hline$\leq 27.5$ & $251(58.5)$ & $29(11.5)$ & 0.670 \\
\hline$>27.5$ & $178(41.5)$ & $23(12.9)$ & \\
\hline \multicolumn{4}{|l|}{ Diabetes mellitus } \\
\hline Yes & $35(8.2)$ & $4(11.4)$ & 0.900 \\
\hline No & $394(91.8)$ & 48 (12.2) & \\
\hline \multicolumn{4}{|l|}{ Tumors' factor } \\
\hline Lesion & & NA & NA \\
\hline Benign & $10(2.3)$ & & \\
\hline Malignant & $419(97.7)$ & & \\
\hline \multicolumn{4}{|l|}{ Cancer stage $(n=419)$} \\
\hline 0 & $10(2.4)$ & NA & NA \\
\hline I & $72(17.2)$ & & \\
\hline$\|$ & $111(26.5)$ & & \\
\hline III & $186(44.4)$ & & \\
\hline IV & $40(9.5)$ & & \\
\hline \multicolumn{4}{|l|}{ T stage $(n=419)$} \\
\hline $\mathrm{T} 1$ & $43(10.3)$ & NA & NA \\
\hline T2 & $61(14.6)$ & & \\
\hline Т3 & 224 (53.5) & & \\
\hline T4 & $91(21.7)$ & & \\
\hline \multicolumn{4}{|l|}{ Preoperative CRT } \\
\hline Yes & $46(10.7)$ & $12(26.1)$ & $0.003^{*}$ \\
\hline No & $383(89.3)$ & $40(10.4)$ & \\
\hline \multicolumn{4}{|l|}{ Size of tumor (mm) } \\
\hline$\leq 42.5$ & $231(53.8)$ & $23(10.0)$ & 0.140 \\
\hline$>42.5$ & $198(46.2)$ & $29(14.6)$ & \\
\hline \multicolumn{4}{|l|}{ Operations' factor } \\
\hline \multicolumn{4}{|c|}{ Simultaneous resection of other organs } \\
\hline No & $360(83.9)$ & $47(13.0)$ & 0.180 \\
\hline Yes & $69(16.1)$ & $5(7.2)$ & \\
\hline Adjacent organs & $49(11.4)$ & & \\
\hline Liver & $20(4.7)$ & & \\
\hline
\end{tabular}

Table 1. Continued

\begin{tabular}{|c|c|c|c|}
\hline Characteristic & Total & $\mathrm{AL}$ & $\mathrm{P}$-value for $\mathrm{AL}$ \\
\hline \multicolumn{4}{|c|}{ Laparoscopic resection } \\
\hline Yes & $192(44.8)$ & $20(10.4)$ & 0.330 \\
\hline No & $237(55.2)$ & $32(13.5)$ & \\
\hline \multicolumn{4}{|c|}{ Type of operation } \\
\hline LAR & $252(58.7)$ & 47 (18.7) & $<0.001^{*}$ \\
\hline$A R$ and $L C$ & $177(41.3)$ & $5(2.8)$ & \\
\hline \multicolumn{4}{|c|}{ Operating time (min) } \\
\hline$\leq 180.5$ & $269(62.7)$ & $30(11.1)$ & 0.430 \\
\hline$>180.5$ & $160(37.3)$ & $22(13.8)$ & \\
\hline \multicolumn{4}{|l|}{ Blood loss (mL) } \\
\hline$\leq 105$ & 327 (76.2) & $41(12.5)$ & 0.640 \\
\hline$>105$ & $102(23.8)$ & $11(10.8)$ & \\
\hline \multicolumn{4}{|c|}{ Splenic flexure mobilization } \\
\hline Yes & $115(26.8)$ & $14(12.2)$ & 0.980 \\
\hline No & $314(73.2)$ & $38(12.1)$ & \\
\hline \multicolumn{4}{|l|}{ ICG FA } \\
\hline Yes & $239(55.7)$ & $21(8.8)$ & $0.020^{\star}$ \\
\hline No & $190(44.3)$ & $31(16.3)$ & \\
\hline \multicolumn{4}{|c|}{ Change of transection line ${ }^{a}$} \\
\hline Yes & $50(20.9)$ & $6(12.0)$ & 0.370 \\
\hline No & $189(79.1)$ & $15(7.9)$ & \\
\hline \multicolumn{4}{|c|}{ Height of anastomosis $(\mathrm{cm})^{b}$} \\
\hline$\leq 6.5$ & $39 / 169(23.1)$ & $39(23.1)$ & $<0.001^{*}$ \\
\hline$>6.5$ & $13 / 260(5.0)$ & $13(5.0)$ & \\
\hline \multicolumn{4}{|l|}{ Air leak test } \\
\hline Yes & $360(83.9)$ & $39(10.8)$ & 0.060 \\
\hline No & $69(16.1)$ & $13(18.8)$ & \\
\hline \multicolumn{4}{|c|}{ Positive air leak test ${ }^{c}$} \\
\hline Yes & $54(15.0)$ & $6(11.1)$ & 0.940 \\
\hline No & $306(85.0)$ & $33(10.8)$ & \\
\hline \multicolumn{4}{|c|}{ Reinforcement of anastomosis } \\
\hline Yes & $223(52.0)$ & $18(8.1)$ & $0.010^{*}$ \\
\hline No & $206(58.0)$ & $34(16.5)$ & \\
\hline \multicolumn{4}{|c|}{ Diverting ileostomy } \\
\hline Yes & $307(71.6)$ & $49(16.0)$ & $<0.001^{*}$ \\
\hline No & $122(28.4)$ & $3(2.5)$ & \\
\hline \multicolumn{4}{|l|}{ R1 resection } \\
\hline Yes & $26(6.1)$ & $7(26.9)$ & $0.020^{*}$ \\
\hline No & $403(93.9)$ & $45(11.2)$ & \\
\hline
\end{tabular}

Values are presented as number (\%).

AL, anastomotic leakage; ASA, American Society of Anesthesiologists; PS, physical status; CRT, chemoradiotherapy; LAR, low anterior rectal resection; AR, anterior resection; LC, left colectomy; ICG FA, indocyanine green fluorescence angiography.

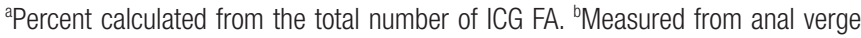
using rigid proctoscope. 'Percent calculated from the total number of air leak test. ${ }^{*} \mathrm{P}<0.05$. 


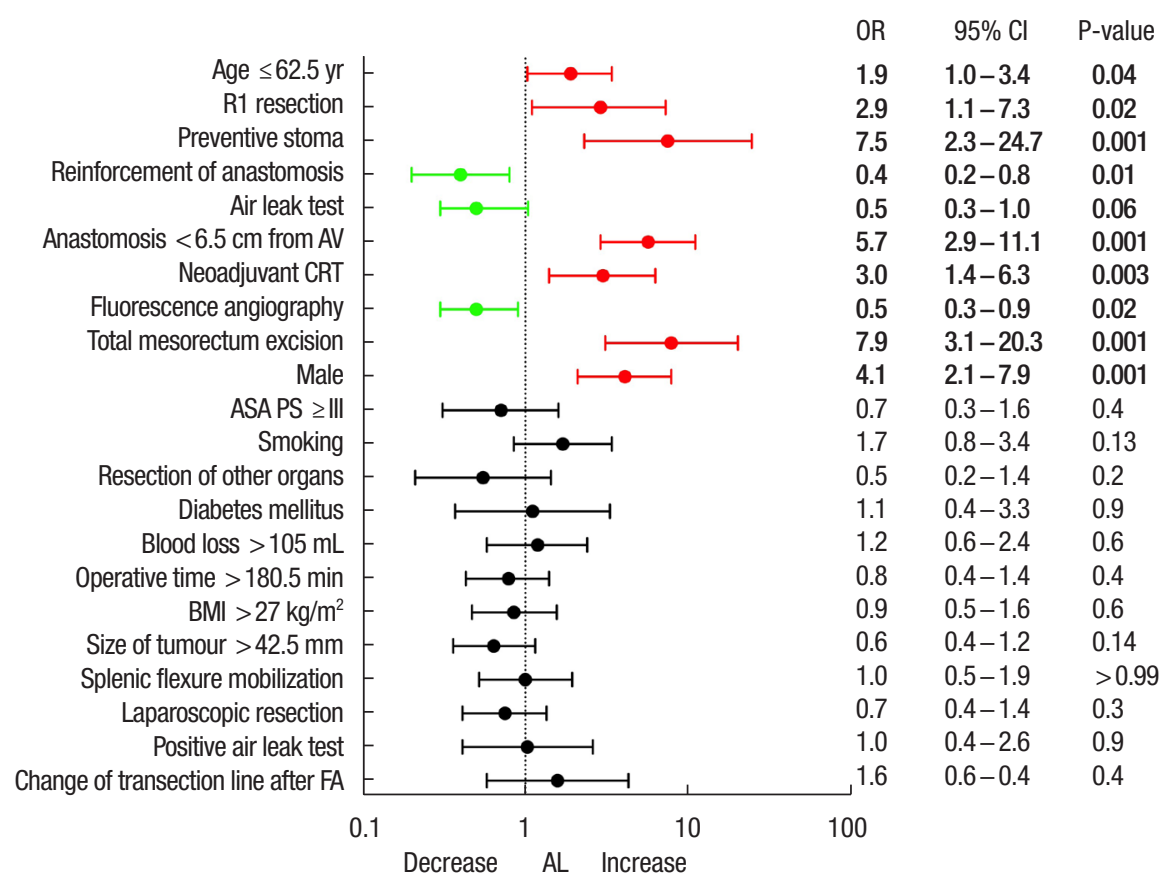

Fig. 1. Flowchart of univariate analysis of factors related to the anastomotic leakage (AL). OR, odds ratio; CI, confidence interval; AV, anal verge; CRT, chemoradiotherapy; ASA, American Society of Anesthesiologists; PS, physical status; BMI, body mass index; FA, fluorescence angiography.

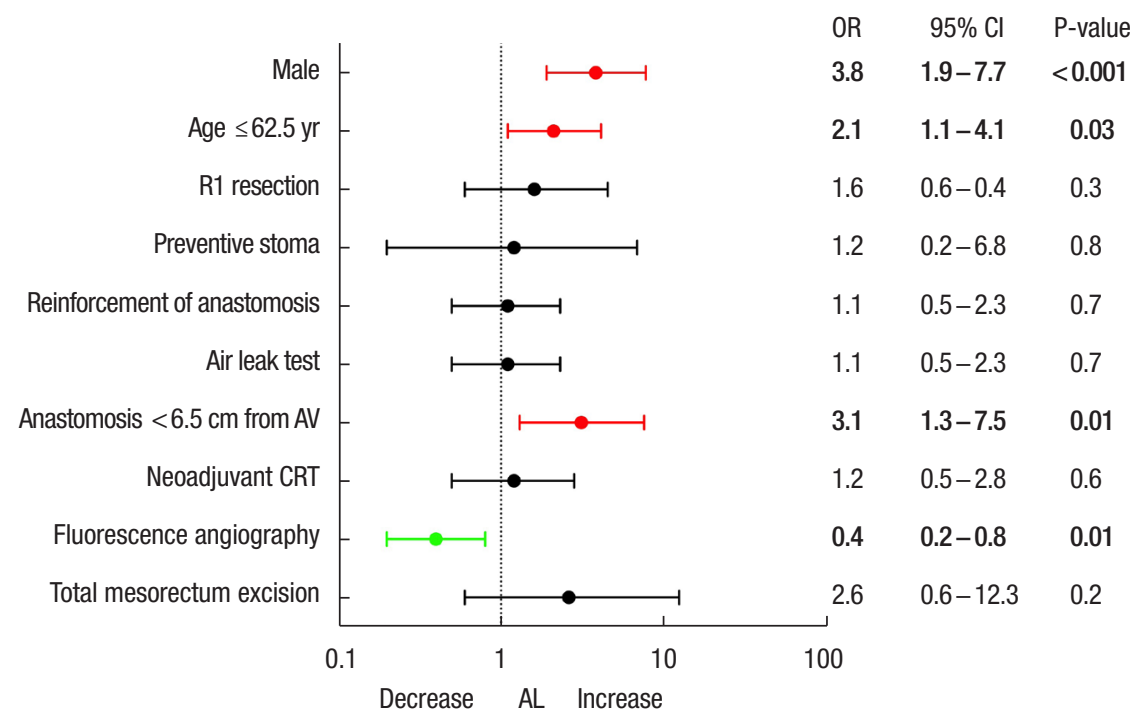

Fig. 2. Flowchart of multivariate analysis of factors related to anastomotic leakage (AL). OR, odds ratio; CI, confidence interval; AV, anal verge; CRT, chemoradiotherapy.

AL. On the other hand, such factors as reinforcement of anastomosis (OR, 0.4; 95\% CI, 0.2-0.8, P=0.01) and FA (OR, 0.5; 95\% CI, $0.3-0.9 ; \mathrm{P}=0.02)$ significantly decrease the rate of AL. In our opinion, the high frequency of $\mathrm{AL}$ in patients with a preventive stoma is associated with the need to form a stoma in patients with a high-risk AL (for example, low anastomoses and it is a matter of statistics). Preventive stoma did not have an independent effect on the AL rate, which was confirmed by the results of multivariate analysis.

In multivariate analysis (Fig. 2), independent variables associated with increase of AL rate were male sex $(\mathrm{OR}, 3.8 ; 95 \% \mathrm{CI}$, 1.9-7.7; $\mathrm{P}<0.001$ ), low anastomosis (OR, 3.1; 95\% CI, 1.3-7.5, $\mathrm{P}=0.01)$ and age of $\leq 62.5$ years $(\mathrm{OR}, 2.1 ; 95 \% \mathrm{CI}, 1.1-4.1 ; \mathrm{P}=$ $0.03)$. Only ICG FA was found as independent factor reducing 


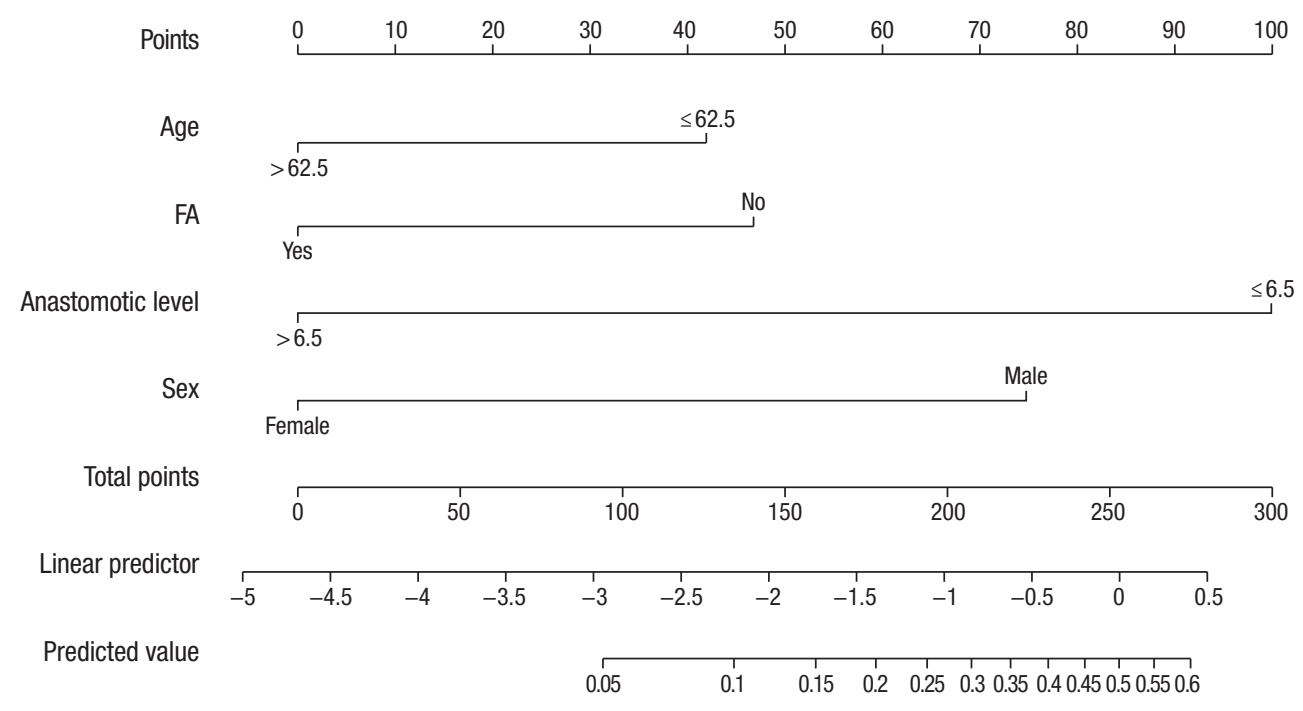

Fig. 3. A nomogram for predicting individual risk of leakage for colorectal anastomosis. After projecting a vertical line on the scale 'points', the total sum is calculated. Projection of vertical line from the scale 'total points' to 'predictive value' gives the probability of anastomotic leakage. FA, fluorescence angiography.

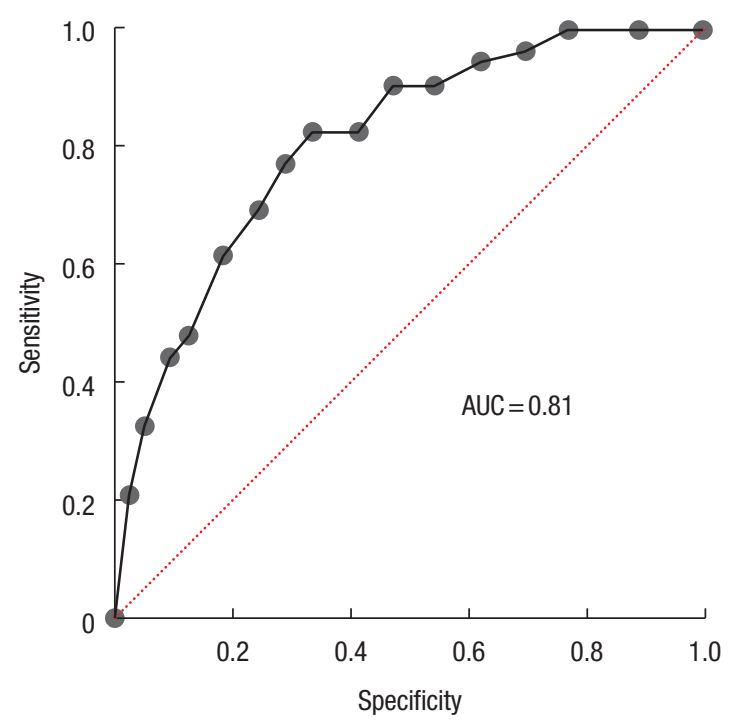

Fig. 4. The receiver-operating characteristic curve for the prediction model. The area under the curve (AUC) was 0.81 (95\% confidence interval, 0.75-0.87).

colorectal AL (OR, 0.4; 95\% CI, 0.2-0.8; $\mathrm{P}=0.01$ ).

The nomogram of AL (Fig. 3) was created based on multivariate logistic regression analysis. The area under the curve was 0.81 ( $95 \%$ CI, 0.75- $0.87 ; \mathrm{P}=0.0001$ ) (Fig. 4) and the concordance index was 0.81 , that indicating well predictive ability.

\section{DISCUSSION}

The presented retrospective study demonstrated AL rate of all grades for colorectal anastomosis of $12.1 \%$. Seven variables were associated with increased risk of AL and 3 with decrease risk in univariate analysis. However logistic regression allowed to identify only 4 independent risk factors of AL. Two of them, i.e., male sex and age younger than 62 years, were patient-related. According to the meta-analyses of Pommergaard et al. [18], which included 110,272 patients from 23 studies, male sex (OR, 1.48; 95\% CI, 1.37-1.60) is likely to be a risk factor for AL, though the quality of the evidence was low. In our study male sex was the most significant independent factor (OR, 3.8; 95\% CI, 1.9-7.7; $\mathrm{P}<0.01$ ), which can be explained by prevalence of rectal carcinomas in presented series of patients, where male narrow pelvis and complex anatomy may contribute to technical difficulties with the formation of colorectal anastomosis [19].

Another patient-related factor associated with increased risk of $\mathrm{AL}$ in presented study was the age of $\leq 62.5$ years. The abovementioned meta-analyses [18] revealed that age (OR, 0.99; 95\% CI, 0.89-1.10) was not a risk factor for AL. Contrary, Zaimi et al. [20] in his study, demonstrated the increase of incidence of colorectal AL with decreasing age: in patients $\geq 80$ years old, $4.9 \%$; 70 to 80 years old, $5.4 \%$; 60 to 69 years old, $5.5 \%$; and $<60$ years old, 6.4\% $(\mathrm{P}<0.001)$. Multivariate analysis showed that age was protective for AL (OR, 0.96 per 5 years; 95\% CI, 0.94-0.98; $\mathrm{P}<$ 0.001). In accordance with the results of an experimental study [21], aging tissues demonstrate more chronic inflammation. Hypothetically, chronic inflammation in aging tissues enables anastomotic healing preventing an exceeded inflammatory response [22]. However, considering the presence of vascular disorders in the mesentery of the colon in elderly patients (for example, atherosclerosis), ICG FA is necessary for an adequate assess the perfusion of the anastomosis. 
In terms of surgery-related risk factors only low anastomosis, i.e. below $6.5 \mathrm{~cm}$ from anal verge, in our study was associated with a higher rate of $\mathrm{AL}(\mathrm{OR}, 3.1 ; 95 \% \mathrm{CI}, 1.3-7.5 ; \mathrm{P}=0.01)$. The factor of low anastomosis $[3,18]$ or low rectal tumor [5-7] is the most univocal in literature.

Surgeon's assessment of risk of AL demonstrated a low predictive value of $62 \%$ of sensitivity and $52 \%$ of specificity [23]. Intraoperative air or dye test of anastomotic integrity is one of the most reproducible in routine colorectal surgery [24]. Interestingly, that air leak test per se demonstrated strong tendency to reduce AL (OR, 0.5; 95\% CI, 0.3-1.0; $\mathrm{P}=0.06$ ) in presented study, though if test was positive it played no role for $\mathrm{AL}$ (OR, 1.0; 95\% CI, 0.4-1.0; $\mathrm{P}=0.9$ ). One plausible explanation for this finding is that the positive leak test urges surgeon to reinforce the line of stapled anastomosis by additional hand sutures or create defunctioning stoma.

Besides the leak-proof stitches and no-tension between anastomosed bowel ends, good blood perfusion of intestinal wall is a prerequisite of successful healing. Conventional assessment of intestinal perfusion based on evaluation of pulsation of vessels, bowel color, and bleeding from the marginal artery is very subjective.

Up to date, the results of 2 meta-analyses of the use of ICG FA in colorectal surgery available $[25,26]$. The meta-analysis of BlancoColino and Espin-Basany [25] combining results of 5 non-randomized studies and 1,302 patients showed that FA in colorectal cancer surgery significantly reduced the AL rate $(\mathrm{OR}, 0.34 ; 95 \%$ $\mathrm{CI}, 0.16-0.74 ; \mathrm{P}=0.006)$ and even greater reducing rate of $\mathrm{AL}$ in rectal cancer surgery $(\mathrm{OR}, 0.19 ; 95 \% \mathrm{CI}, 0.05-0.75 ; \mathrm{P}=0.02)$. According to Shen et al. [26] significant benefit in reducing the incidence of colorectal AL of FA was also identified (OR, 0.27; 95\% CI, 0.13-0.53; $\mathrm{P}<0.001$ ). Results of our study also confirm that ICG FA is a modifiable independent factor reducing an incidence of colorectal AL (OR, 0.4\%; 95\% CI, 0.2-0.8; P = 0.01).

An obvious limitation of this study is its single-center and retrospective design. On the other hand, the homogeneous population of patients, i.e. all had colorectal anastomoses, which are most vulnerable for leak is a strength of our study. Also, we evaluated $\mathrm{AL}$, including radiologic $\mathrm{AL}$, at 30-day follow-up and this allowed to get an actual rate of AL even in the presence of diverting ileostomy. Up to our knowledge, the suggested nomogram is the first one, which takes into consideration such factor as ICG FA.

In conclusion, this study showed that male sex and anastomosis below $6.5 \mathrm{~cm}$ from anal verge were independent risk factors of colorectal AL. Age over 62.5 years and ICG FA had protective effect on colorectal anastomosis. A suggested nomogram, which takes into consideration ICG FA, might be able to identify the risk of AL for colorectal anastomosis.

\section{CONFLICT OF INTEREST}

No potential conflict of interest relevant to this article was reported.

\section{FUNDING}

None.

\section{ORCID}

Mikhail Alekseev, https://orcid.org/0000-0001-5655-6567

Evgeny Rybakov, https://orcid.org/0000-0002-3919-9067

Evgeniy Khomyakov, https://orcid.org/0000-0002-3399-0608

Irina Zarodnyuk, https://orcid.org/0000-0002-9442-7480

Yuri Shelygin, https://orcid.org/0000-0002-8480-9362

\section{REFERENCES}

1. Rygick AN, Juchvidova GM, Rivkin VL, Gureeva CF, Militarev JM. Colo-rectal anastomosis with a suturing apparatus in resection of the rectum and colon. Gut 1967;8:189-91.

2. Griffen FD, Knight CD Sr, Whitaker JM, Knight CD Jr. The double stapling technique for low anterior resection. Results, modifications, and observations. Ann Surg 1990;211:745-51.

3. Davis B, Rivadeneira DE. Complications of colorectal anastomoses: leaks, strictures, and bleeding. Surg Clin North Am 2013;93:61-87.

4. Chambers WM, Mortensen NJ. Postoperative leakage and abscess formation after colorectal surgery. Best Pract Res Clin Gastroenterol 2004;18:865-80.

5. Bertelsen CA, Andreasen AH, Jørgensen T, Harling H; Danish Colorectal Cancer Group. Anastomotic leakage after anterior resection for rectal cancer: risk factors. Colorectal Dis 2010;12:37-43.

6. Eberl T, Jagoditsch M, Klingler A, Tschmelitsch J. Risk factors for anastomotic leakage after resection for rectal cancer. Am J Surg 2008;196:592-8.

7. Tortorelli AP, Alfieri S, Sanchez AM, Rosa F, Papa V, Di Miceli D, et al. Anastomotic leakage after anterior resection for rectal cancer with mesorectal excision: incidence, risk factors, and management. Am Surg 2015;81:41-7.

8. Baek SJ, Kim J, Kwak J, Kim SH. Can trans-anal reinforcing sutures after double stapling in lower anterior resection reduce the need for a temporary diverting ostomy? World J Gastroenterol 2013;19: 5309-13.

9. Xiao L, Zhang WB, Jiang PC, Bu XF, Yan Q, Li H, et al. Can transanal tube placement after anterior resection for rectal carcinoma reduce anastomotic leakage rate? A single-institution prospective randomized study. World J Surg 2011;35:1367-77.

10. Zhao WT, Li NN, He D, Feng JY. Transanal tube for the prevention of anastomotic leakage after rectal cancer surgery: a systematic review and meta-analysis. World J Surg 2017;41:267-76.

11. Bakker IS, Morks AN, Ten Cate Hoedemaker HO, Burgerhof JGM, Leuvenink HG, van Praagh JB, et al. Randomized clinical trial of biodegradeable intraluminal sheath to prevent anastomotic leak after stapled colorectal anastomosis. Br J Surg 2017;104: 1010-9.

12. Jafari MD, Wexner SD, Martz JE, McLemore EC, Margolin DA, 
Sherwinter DA, et al. Perfusion assessment in laparoscopic leftsided/anterior resection (PILLAR II): a multi-institutional study. J Am Coll Surg 2015;220:82-92.

13. Ris F, Liot E, Buchs NC, Kraus R, Ismael G, Belfontali V, et al. Multicentre phase II trial of near-infrared imaging in elective colorectal surgery. Br J Surg 2018;105:1359-67.

14. Zheng H, Wu Z, Wu Y, Mo S, Dai W, Liu F, et al. Laparoscopic surgery may decrease the risk of clinical anastomotic leakage and a nomogram to predict anastomotic leakage after anterior resection for rectal cancer. Int J Colorectal Dis 2019;34:319-28.

15. Kim CH, Lee SY, Kim HR, Kim YJ. Nomogram prediction of anastomotic leakage and determination of an effective surgical strategy for reducing anastomotic leakage after laparoscopic rectal cancer surgery. Gastroenterol Res Pract 2017;2017:4510561.

16. Hoshino N, Hida K, Sakai Y, Osada S, Idani H, Sato T, et al. Nomogram for predicting anastomotic leakage after low anterior resection for rectal cancer. Int J Colorectal Dis 2018;33:411-8.

17. Rahbari NN, Weitz J, Hohenberger W, Heald RJ, Moran B, Ulrich A, et al. Definition and grading of anastomotic leakage following anterior resection of the rectum: a proposal by the International Study Group of Rectal Cancer. Surgery 2010;147:339-51.

18. Pommergaard HC, Gessler B, Burcharth J, Angenete E, Haglind E, Rosenberg J. Preoperative risk factors for anastomotic leakage after resection for colorectal cancer: a systematic review and metaanalysis. Colorectal Dis 2014;16:662-71.

19. Targarona EM, Balague C, Pernas JC, Martinez C, Berindoague R, Gich I, et al. Can we predict immediate outcome after laparoscopic rectal surgery? Multivariate analysis of clinical, anatomic, and pathologic features after 3-dimensional reconstruction of the pelvic anatomy. Ann Surg 2008;247:642-9.
20. Zaimi I, Sparreboom CL, Lingsma HF, Doornebosch PG, Menon AG, Kleinrensink GJ, et al. The effect of age on anastomotic leakage in colorectal cancer surgery: a population-based study. J Surg Oncol 2018;118:113-20.

21. Franceschi C, Capri M, Monti D, Giunta S, Olivieri F, Sevini F, et al. Inflammaging and anti-inflammaging: a systemic perspective on aging and longevity emerged from studies in humans. Mech Ageing Dev 2007;128:92-105.

22. Wu Z, Vakalopoulos KA, Boersema GS, Kroese LF, Lam KH, van der Horst PH, et al. The prevention of colorectal anastomotic leakage with tissue adhesives in a contaminated environment is associated with the presence of anti-inflammatory macrophages. Int J Colorectal Dis 2014;29:1507-16.

23. Karliczek A, Harlaar NJ, Zeebregts CJ, Wiggers T, Baas PC, van Dam GM. Surgeons lack predictive accuracy for anastomotic leakage in gastrointestinal surgery. Int J Colorectal Dis 2009;24: 569-76.

24. Allaix ME, Lena A, Degiuli M, Arezzo A, Passera R, Mistrangelo $\mathrm{M}$, et al. Intraoperative air leak test reduces the rate of postoperative anastomotic leak: analysis of 777 laparoscopic left-sided colon resections. Surg Endosc 2019;33:1592-9.

25. Blanco-Colino R, Espin-Basany E. Intraoperative use of ICG fluorescence imaging to reduce the risk of anastomotic leakage in colorectal surgery: a systematic review and meta-analysis. Tech Coloproctol 2018;22:15-23.

26. Shen R, Zhang Y, Wang T. Indocyanine green fluorescence angiography and the incidence of anastomotic leak after colorectal resection for colorectal cancer: a meta-analysis. Dis Colon Rectum 2018;61:1228-34. 